\title{
Local distribution analysis of cytotoxic molecules in liver allograft is helpful for the diagnosis of acute cellular rejection after orthotopic liver transplantation
}

Long Cheng ${ }^{1,2}$, Fuzhou Tian², Lijun Tang ${ }^{2}$, Shuguang Wang ${ }^{3}$, Geng Chen ${ }^{3}$, Guangjie Duan ${ }^{1}$ and Xiaochu Yan ${ }^{1 *}$

\begin{abstract}
Background: As it is often difficult for a transplant pathologist to make a definite diagnosis of acute cellular rejection (ACR) by routine morphological analysis of liver allograft biopsy, supplementary methods and objective markers are needed to facilitate this determination.

Methods: To evaluate the diagnostic value of cytotoxic molecules in ACR episodes, immunohistochemical staining for perforin, granzyme B and T-cell intracellular antigen-1 (TIA-1) were performed in liver allograft biopsies. The positive cells in the portal tract area and lobules were counted separately to investigate the distribution of the cytotoxic molecules.

Results: The immunohistochemical study showed that the overall positive rates for the three markers were not significantly different between the ACR and non-ACR groups. However, in the portal tract area, perforin-, granzyme B- and TIA-1-positive cells in the ACR group were significantly more than those in the non-ACR groups. In the lobules, perforin- and granzyme B-positive cells in the ACR group were significantly more than those in the biliary complication and opportunistic infection groups, while TIA-1-positive cells was significantly fewer than those in non-ACR groups. The numbers of positive cells in the portal tract area correlated with the rejection activity index of ACR.
\end{abstract}

Conclusions: These results indicate that, though the overall positive rates have nonsense in ACR diagnosis, the quantification and local distribution analysis of cytotoxic molecule positive cells in liver tissue is helpful for differential diagnosis and severity evaluation of ACR following liver transplantation.

Virtual slides: The virtual slide(s) for this article can be found here: http://www.diagnosticpathology.diagnomx. eu/vs/2292255038100487

Keywords: Liver transplantation, Acute cellular rejection (ACR), Rejection activity index (RAl), Perforin, Granzyme B, T-cell intracellular antigen-1

\footnotetext{
* Correspondence: yxctmmu@163.com

${ }^{1}$ Institute of Pathology, Southwest Hospital, Third Military Medical University,

Chongqing 400038, China

Full list of author information is available at the end of the article
} 


\section{Introduction}

With the incidence reportedly ranging from $30 \%$ to $70 \%$, acute cellular rejection (ACR) is one of the most common complications after orthotopic liver transplantation (OLT) $[1,2]$. The appropriate immunosuppressive therapy for ACR, which is important for reducing morbidity and improving the life quality of recipients, is based on precise diagnoses and grading. At present, the Banff schema is accepted as the diagnostic judge standard for ACR, which is morphologically characterized by lymphocyte infiltration of portal tracts, bile duct damage and endothelitis in portal and hepatic central veins [3-5]. However, due to the overlapping histological features between ACR and other complications following liver transplantation, differential diagnoses and severity evaluations for ACR are often difficult. This prompted us to look for some potential methods and molecular markers helpful for diagnosing ACR and evaluating its severity.

It is generally accepted that $\mathrm{T}$ cell-mediated immune reactions play a pivotal role in the pathogenesis of ACR, and CD8+ cytotoxic T cells induce target cell death during acute allograft rejection in liver allograft tissues [6-8]. Cytotoxic molecules such as perforin, granzyme B and Tcell intracellular antigen-1 (TIA-1) are present in the cytoplasmic granules of cytotoxic $\mathrm{T}$ cells and function at the effector end of the acute rejection process [9]. Nevertheless, a study also showed that cytotoxic molecules can also mediate liver graft rejection in the absence of CD8+ T cells [10]. Thus, cytotoxic protein detection might be a sensitive and objective method for predicting acute rejection injury. It has been reported that granzyme B and perforin played predictive roles in acute rejection diagnosis after renal, heart and intestinal transplantation [11-14]. Moreover, in acute rejection after kidney transplantation, the quantity and intensity of TIA-1 expression are both increased, and this variation can reflect rejection severity to some extent [15]. However, the diagnostic value of these cytotoxic molecules in acute cellular rejection after liver transplantation has not yet been clearly elucidated.

To further evaluate the role of cytotoxic molecules in ACR diagnosis, immunohistological staining of perforin,

Table 1 Underlying diseases of the transplant recipients

\begin{tabular}{ll}
\hline Primary disease & $\begin{array}{l}\text { No. of } \\
\text { patients }\end{array}$ \\
\hline Posthepatitic cirrhosis & 17 \\
\hline Hepatocellular carcinoma & 15 \\
\hline Posthepatitic cirrhosis complicated by hepatocellular & 18 \\
carcinoma & 17 \\
\hline Severe hepatitis & 2 \\
\hline Alcoholic cirrhosis & 2 \\
\hline Primary biliary cirrhosis & 2 \\
\hline Primary hepatic amyloidosis & \\
\hline
\end{tabular}

granzyme B and TIA-1 was performed on allograft liver biopsies. As it was noted that different liver diseases mainly target at different tissues and cells of liver, the positive cells in the portal tract area and lobules were counted separately to investigate the local distribution characteristics of the cytotoxic molecules. Meanwhile, correlations between the numbers of positive cells and the Banff rejection activity index (RAI) were analyzed.

\section{Materials and methods}

\section{Patients and clinic materials}

The liver tissue samples were obtained from the Institute of Hepatobiliary Surgery of Southwest Hospital, the Third Military Medical University. Written informed consent was obtained from all patients and this study was carried out in accordance with the principles of the Helsinki Declaration and approved by the Ethical Committee of the Third Military Medical University, Chongqing, Peoples Republic of China.

Between February 2000 and December 2006, 234 samples were obtained by percutaneous needle biopsy from patients that underwent orthotopic liver transplantation (OLT) in Southwest hospital. A total of 108 biopsy samples from 73 patients ( 66 males and 7 females) were enrolled in the study based on the following criteria: those with more than 10 portal tracts in each biopsy; those with integrated clinical follow-up information. The ages of the patients ranged from 18 to 69 years and their primary clinical diagnoses are listed in Table 1 .

All patients enrolled in the study were treated with glucocorticoid, Mycophenolate Mofetil and cyclosporine A or tacrolimus after surgery. Glucocorticoid was stopped within three months, and cyclosporine A or tacrolimus was administered separately to maintain immunosuppression. Complications were diagnosed based on clinical and biochemical data in combination with pathological evaluation of allograft liver needle biopsy specimens. ACR episodes were generally treated with daily administration of methylprednisolone $(20 \mathrm{mg} / \mathrm{kg})$ for three consecutive days.

\section{Histological observation}

Biopsy specimens were fixed in $10 \%$ buffered formalin, embedded in paraffin, sectioned serially at a $4 \mu \mathrm{m}$ thickness, and de-waxed. H\&E was performed routinely. The RAI for each specimen was scored according to the Banff consensus by two independent qualified transplant pathologists unaware of the clinical data of the patients [3].

\section{Immunohistological staining}

Monoclonal antibodies against perforin, granzyme B (DAKO, Glostrup, Denmark) and TIA-1 (abcam, Cambridge, UK.) were applied to the above sections. Antigens were retrieved in citrate buffer in a microwave oven and endogenous peroxidase activity was blocked 
with 3\% hydrogen peroxide. Then, sections were incubated at $4^{\circ} \mathrm{C}$ with primary antibodies (with a dilution of 1:200 for perforin, 1:200 for granzyme B and 1:100 for TIA-1) overnight and the Envision ${ }^{\mathrm{TM}}$ staining (DAKO, Glostrup, Denmark) procedure was performed. Sections with the primary antibody application omitted served as a negative control.

Brown granular staining was considered to be a positive signal for the IHC assay. The positive cells were counted under light microscope according to the previous description with some modifications [8]. The positive cells in the portal tract area and lobules were counted separately to investigate the distribution of the cytotoxic molecules. For each slide, the positive cells in least 10 portal tracts and 10 high power fields (HPF) in the lobules were counted under the light microscope (Olympus BX51, Japan). The average positive cells per portal tract and per HPF in the lobules were calculated.

\section{Statistical analysis}

Statistical analyses were performed using SPSS Version 13.0 for Windows (Statistical Package for the Social Sciences; SPSS, Munich, Germany). Groups were compared using Mann-Whitney $U$-tests, and Spearman's Rank test was performed to look for correlations between the number of positive cells and RAI score. $P<0.05$ was considered statistically significant.

\section{Results}

\section{Histological observation}

In the 108 cases, 62 cases were diagnosed as ACR and 46 were non-ACR, including 19 biliary complications (BC), 6 ischemic/reperfusion injuries (I/R), 6 opportunistic infections (OI) and 15 undefined complications (UD).
In the ACR cases, varying degrees of lymphocytic infiltration of portal tracts, bile duct damage and subendothelialitis were recognized in the pathologically examined specimens. The numbers of samples with RAI scores of 1, 2, 3, 4, 5, 6, 7 and 8 were 4, 9, 9, 15, 9, 6, 6 and 4 cases respectively. (Figure 1A-B).

\section{The expression and distribution of cytotoxic effector molecules in ACR and non-ACR tissue}

Perforin, granzyme B and TIA-1 were mainly located in the cytoplasm of inflammatory cells in portal tracts and lobules, and they were frequently observed in the epithelia of interlobular bile ducts and subendothelial portions of portal veins in ACR, (Figure 2 and 3). There was no significant difference in the positive rates for perforin, granzyme B and TIA-1 between ACR and non-ACR samples $(98.4 \% \%$ versus $95.6 \%, 96.8 \%$ versus $91.3 \%$ and $100 \%$ versus $100 \%$, respectively). However, the number and distribution of positive cells were different. There were significantly more perforin-, granzyme B- and TIA1-positive cells in the portal tract area in the ACR group than in the non-ACR groups, and there was no significant difference among the non-ACR groups. The numbers of perforin- and granzyme B-positive cells in lobules in the ACR group were significantly greater than those in the BC, OI and UD groups, but they were similar to that in the I/R group. The numbers of TIA-1positive cells in lobules in the ACR group was significantly lower than those in $\mathrm{BC}, \mathrm{I} / \mathrm{R}$ and OI groups, but was similar to that in UD group. (Figure 4) The above results indicate that the positive cell number, but not the positive rate of cytotoxic molecules in liver biopsies, could be used as a statistical indicator of ACR.
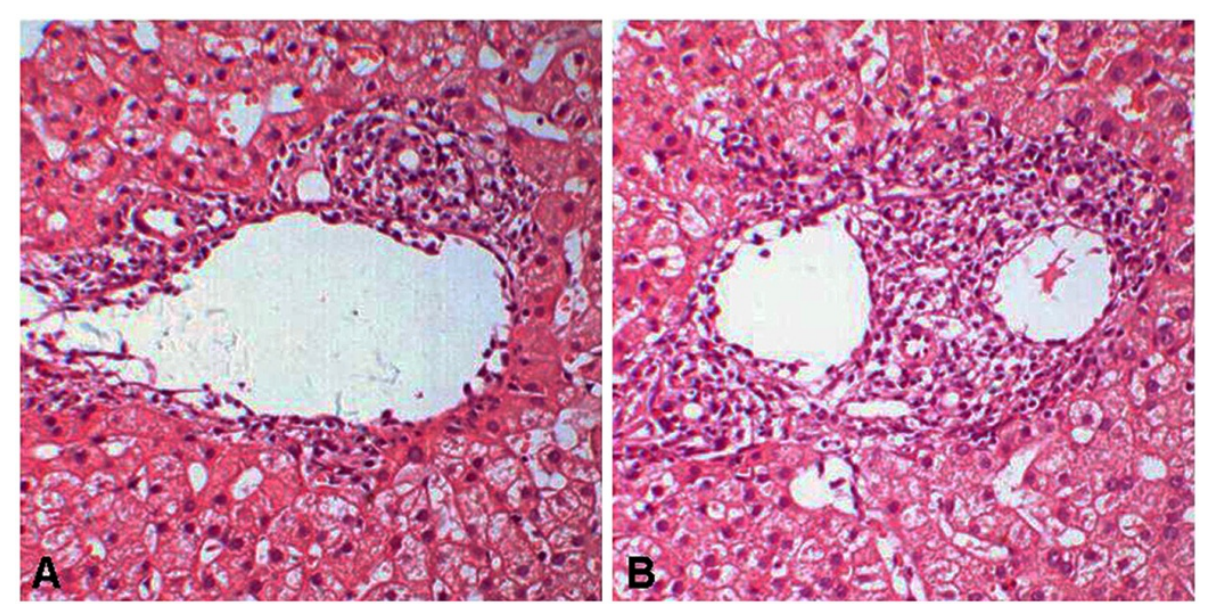

Figure 1 The histopathological features of acute cellular rejection. Typical histopathological changes, including portal inflammation, bile duct inflammation/damage and venous endotheliatis, so called "triads," appeared in mild (A, RAl = 4) and moderate (B, RAl $=7)$ acute cellular rejection $(H \& E, \times 200)$. 


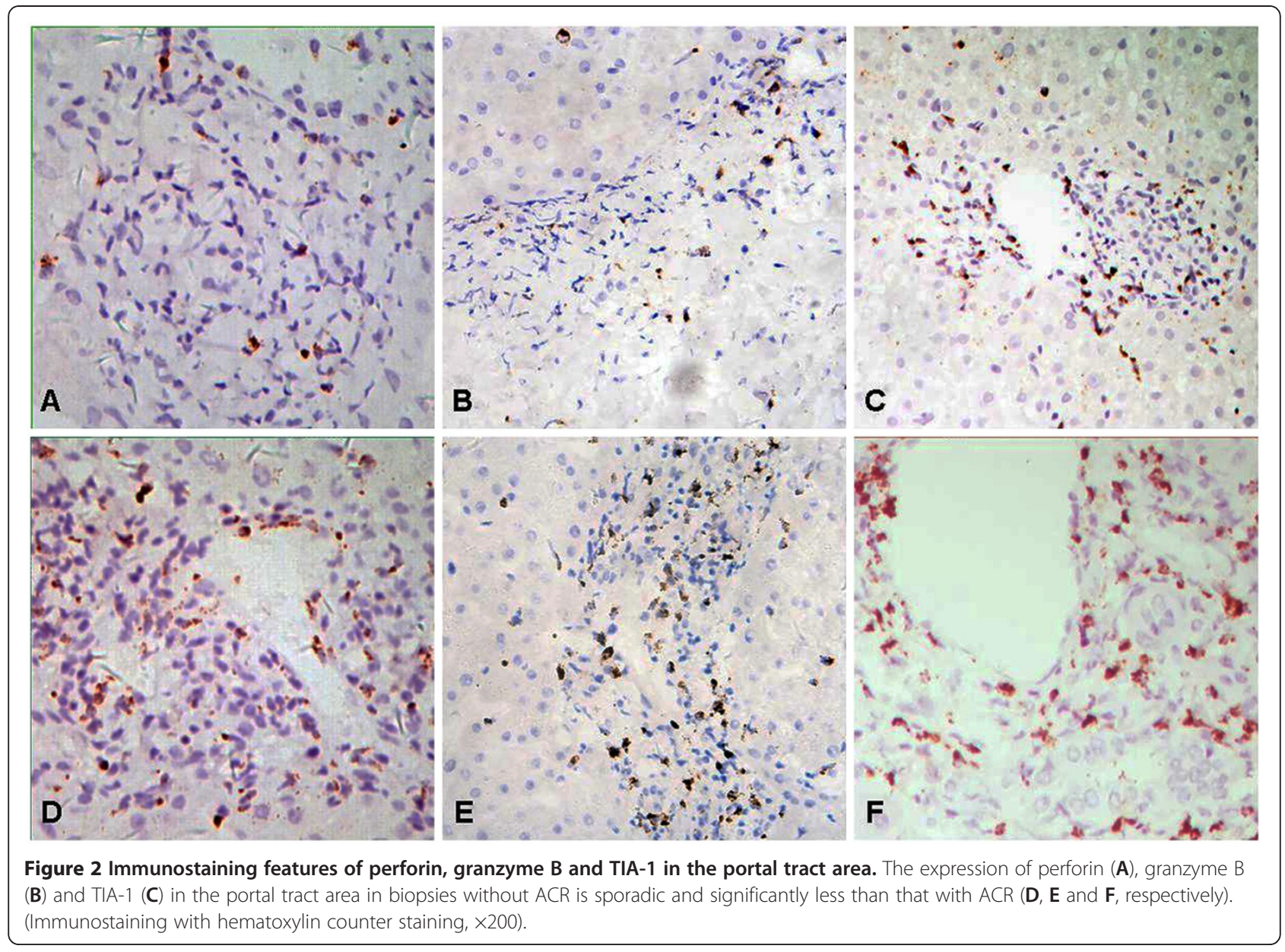

\section{Expression of cytotoxic effector molecules correlates with RAI}

In the ACR group, we recognized a tendency for the number of positive cells to increase as the RAI score rose, so the relationship between the number of positive cells and RAI score was further analyzed. There were a significant positive correlations between the numbers of positive cells in portal tracts and the RAI scores $(\mathrm{r}=0.829$ for perforin, 0.799 for granzyme $\mathrm{B}$ and 0.780 for TIA-1, respectively), (Figure 5). The numbers of positive cells in lobules were not correlated with the RAI score ( $p>0.05)$. These results indicate that immunohistochemical analysis of cytotoxic molecules in the portal tract area of liver might be a useful supplementary tool for the objective evaluation of ACR severity.

\section{Discussion}

Acute cellular rejection (ACR) is still common after liver transplantation (OLT) despite well developed immunosuppressive agents, with incidence ranging from $30 \%$ to $70 \%$ in different series. Multivariate analysis showed that recipient age, underlying liver disease, and Child's class before LT were independently associated with the development of ACR [16]. Although the pathogenesis of ACR remains need to be further elucidated, it is generally accepted that ACR occurrence is mainly due to recognition of donor alloantigen by recipient $\mathrm{T}$ lymphocytes. Following recognition and activation, $\mathrm{T}$ lymphocytes trigger a series of immunoresponses and effect mechanisms. In most cases, ACR responds well to immunosuppressive treatment. However, this should not lead to an underestimation of its importance because immunosuppressive treatment is associated with increased risk for infections, recurrence of virus hepatitis, and metabolic complications such as diabetes mellitus, hyperlipidemia, and hypertension, etc. On the other hand, the repeated ACR episodes without immunosuppressive treatment or with inadequate immunosuppressive therapy might induce the occurrence of chronic rejection which would result in graft loss. So appropriate immunosuppressive therapy for ACR, is critical for reducing morbidity and improving the life quality of recipients, and makes it necessary to diagnose ACR timely and definitely.

Berman et al. summarized the histopathologic features of ACR in three aspects which constitute the basis of 


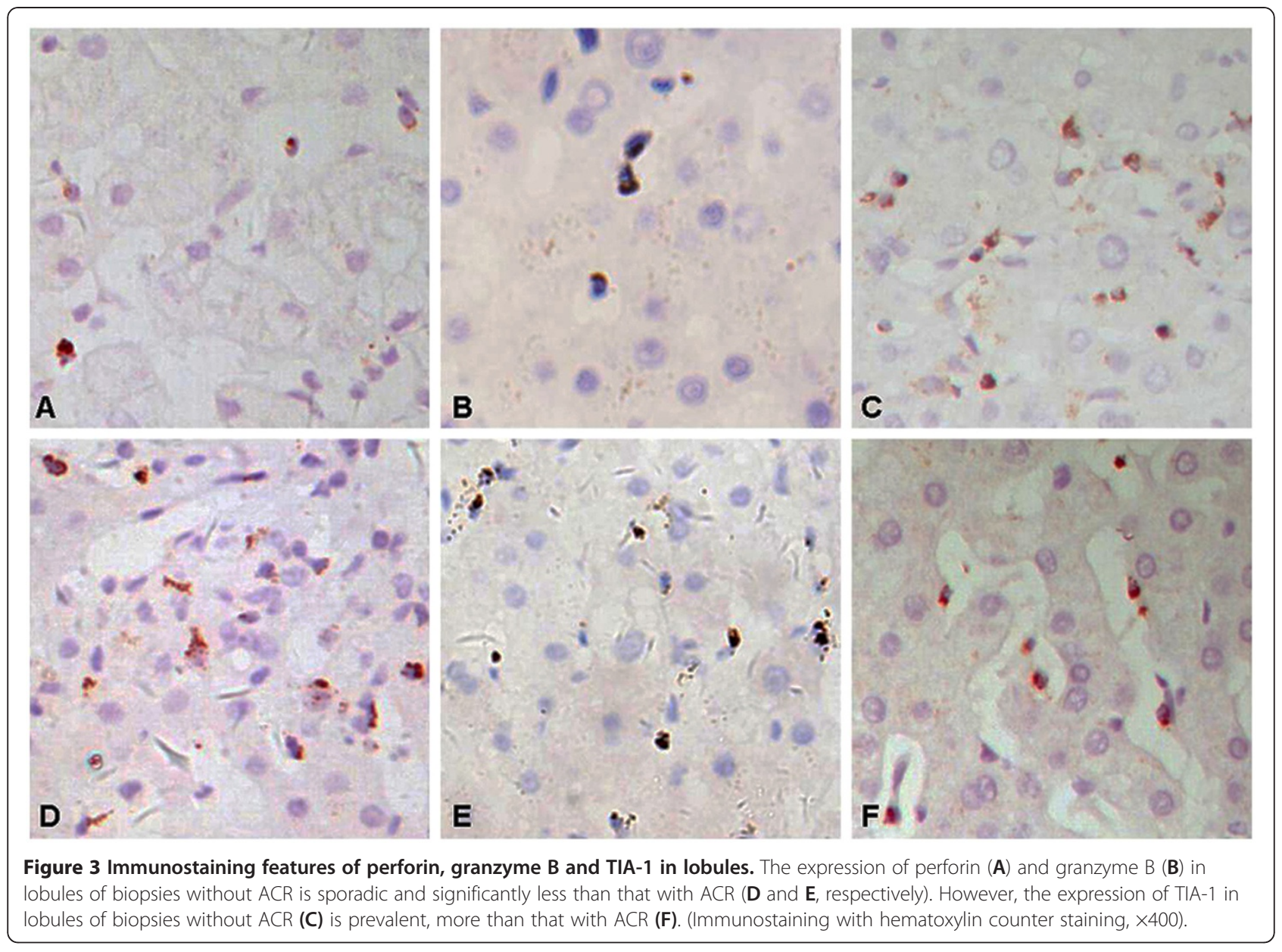

Banff schema: 1) mixed infiltration of inflammatory cells, including mainly mononuclear cells and also various amounts of neutrophils and eosinophils, in the portal area; 2) endothelialitis in portal and hepatic central veins characterized by subendothelial infiltration of inflammatory cells; and 3) bile duct damage with cholangitis and degenerative necrosis of biliary epithelial cells. At present, allograft biopsy remains the 'gold standard' for diagnosing ACR, and the Banff schema is accepted by pathologists as the diagnosing and grading criterion for ACR. However, there are overlapping histological features and clinical manifestation between ACR and other complications following liver transplantation [17], such as ischemic/reperfusion injury, biliary complication, recurrent virus hepatitis, etc. These overlaps make ACR diagnosis and grading often difficult, and urge us to explore some potential methods and molecular markers helpful for diagnosing ACR and evaluating its severity.

Perforin and granzyme B are proteins in the cytoplasmic granules of $\mathrm{T}$ lymphocytes and natural killer cells. Upon release by exocytosis, perforin disrupts lipid membranes and granzyme B accesses the cytosol of target cells, subsequently triggering cell death through apoptosis [18,19]. Animal experiments and clinical studies found that perforin and granzyme B were overexpressed after liver transplantation, which suggested a role in pathogenesis of acute rejection [20,21]. Studies have reported that perforin and granzyme B can be sensitive and specific markers for diagnosing ACR [22,23]. Inconsistent with these reports, in our cohort, perforin and granzyme B were expressed widely in liver allograft biopsies with or without ACR, and no difference in expression rate was observed. This inconsistence may arise from differences in the examination methods and judging criteria. Because of the non-utility of the positive rate for ACR diagnosis, in current study, we focused on quantifying the positive cells and determining their distribution in liver tissue. Our results showed that the numbers of perforin- and granzyme B-positive cells in the portal tract area were significantly greater with ACR than with other complications. However, in the lobule area, there were more positive cells with ACR than with $\mathrm{BC}$ or OP, but a similar amount of cells to that with $\mathrm{I} / \mathrm{R}$ injury. These results are consistent with reports stating that ACR involves not only damage to the portal tract but also lobule injury, and that the cytotoxic $\mathrm{T}$ cells are 


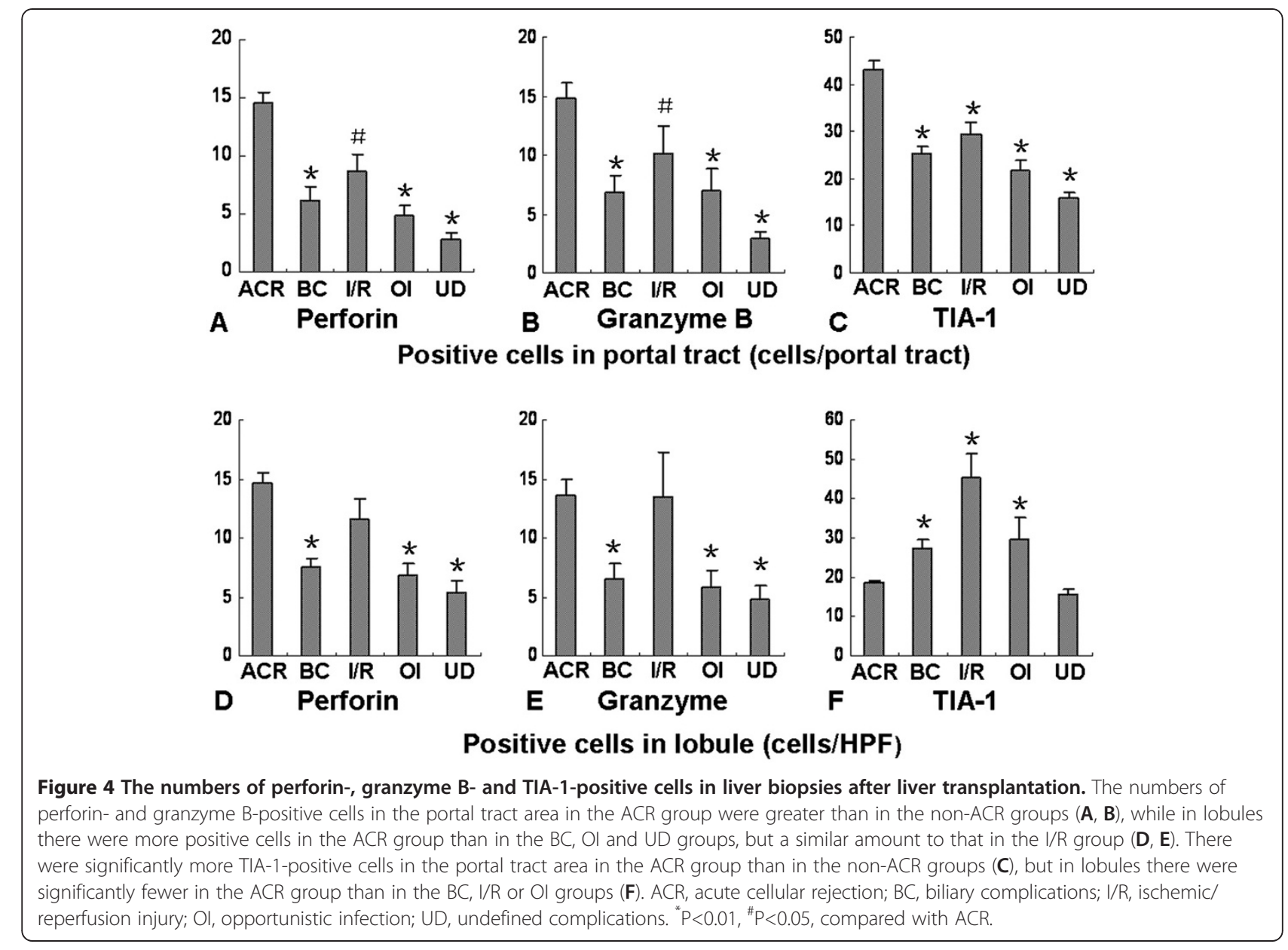

also activated during I/R injury [24,25]. Our study indicates that the quantification of perforin- and granzyme B-positive cells in different areas in liver biopsies could be more informative for ACR diagnosis than mere determination of the positive rate.
Unlike perforin and granzyme $\mathrm{B}$, which are expressed in cytotoxic $\mathrm{T}$ cells and NK cells, TIA-1, also named granule membrane protein-17 (GMP-17), is expressed not only by cytotoxic T cells and NK cells but also by monocytes and neutrophils [26,27]. TIA-1 is the granule
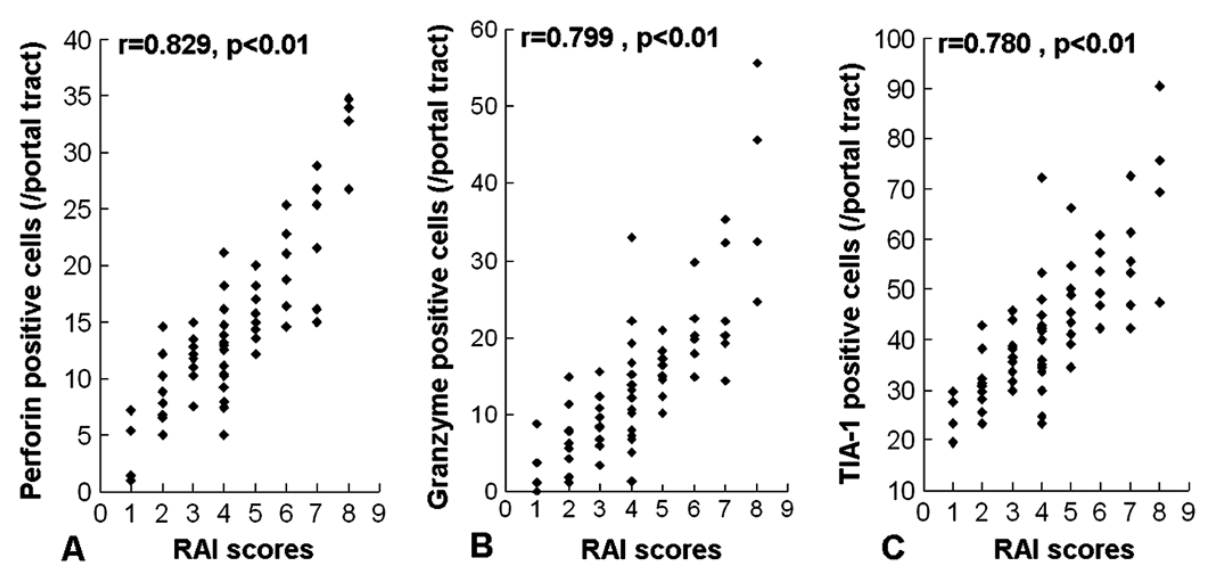

Figure 5 Correlations between perforin-, granzyme B- and TIA-1-positive cells in the portal tract area and the RAI scores. Values for each sample are plotted in each column (A, B and $\mathbf{C}$, respectively). 
component responsible for inducing DNA fragmentation and apoptosis in cytolytic lymphocyte targets. In acute rejection after kidney transplantation, the quantity and intensity of TIA-1 expression increase, and the degree of this variation can reflect rejection severity to some extent $[15,28,29]$. However, the diagnostic value of TIA-1 in acute rejection after liver transplantation has not been determined. Our data show that TIA-1 is also expressed widely in liver allograft biopsies with or without ACR. Interestingly, our results showed that the number of TIA-1-positive cells significantly increased in the portal tract area but not in lobules during ACR episodes. By contrast, during other complications such as biliary complications, opportunistic infections, and preservation/reperfusion injuries, TIA-1-positive cells significantly increased in lobules but not in the portal tract area. These opposite alterations may occur because cytotoxic $\mathrm{T}$ cells are prevalent in the portal tract in ACR cases, while monocytes and neutrophils, which also release TIA-1, are more popular in lobular in biliary complications, opportunistic infections, and preservation/ reperfusion injuries. This distributional difference of TIA-1-positive cells implies that a marked increase in the portal tract combined with insignificant changes in lobules may indicate a diagnosis of ACR. To our knowledge, no previous studies found this pattern of TIA-1 expression in liver grafts. Therefore, the local distribution of TIA-1-positive cells in liver biopsies may provide a morphological means of distinguishing ACR from other complications after liver transplantation.

One study showed that the number of CD8-positive cells correlated with rejection severity in liver allograft tissues. ${ }^{8}$ However, the relationship between rejection severity and the expression of perforin, granzyme $\mathrm{B}$ and TIA-1 has not been determined. Our present data show that the numbers of perforin-, granzyme B- and TIA-1positive cells in the portal tract area correlated with acute rejection severity after liver transplantation. This result is compatible with the notion that the portal tracts are the main targets of ACR and that these cytotoxic molecules are at the effector end of the acute rejection process. Based on our results, we conclude that the identification of perforin, granzyme B and TIA-1 in the portal tract area of liver biopsies would be helpful for determining the severity of ACR.

Immunohistochemical staining has become a routine method in clinical pathological diagnosis. Immunohistochemical assays for perforin, granzyme B and TIA-1 are applicable in most pathology laboratories of large hospitals. ACR pathological diagnoses are based on H\&E findings, according to the Banff schema. Our result raise the possibility that immunohistochemical analysis of cytotoxic molecules has the potential to become a supplementary as well as an objective assessment method for
ACR diagnosis to be used as an adjunct to the Banff schema in the future.

In conclusion, our results indicate that, though the overall positive rates have nonsense in ACR diagnosis, the quantification and local distribution analysis of cytotoxic molecule positive cells in liver tissue is helpful for differential diagnosis and severity evaluation of ACR following liver transplantation.

\section{Abbreviations}

ACR: Acute cellular rejection; RAl: Rejection activity index; TIA-1: T-cell intracellular antigen-1; BC: Biliary complications; IRI: Ischemic/reperfusion injuries; Ol: Opportunistic infections; UD: Undefined complications.

\section{Competing interests}

The authors declare that they have no competing interests.

\section{Authors' contributions}

$L C, F T$ and $L T$ contributed to the research designing, writing of the paper, performing of the research and data analysis. SW, GC and GD participated in the performance of the research. XY participated in research design and the writing of the paper. All authors read and approved the final manuscript.

\section{Acknowledgements}

This study was supported by a grant from the National scientific Foundation of China (No. 30901466).

\section{Author details}

${ }^{1}$ Institute of Pathology, Southwest Hospital, Third Military Medical University, Chongqing 400038, China. ${ }^{2}$ Department of General Surgery, General Hospital of Chengdu Military Command, Chengdu 610083, China. ${ }^{3}$ Institute of Hepatobiliary Surgery, Southwest Hospital, Third Military Medical University, Chongqing 400038, China.

Received: 24 September 2012 Accepted: 24 October 2012 Published: 30 October 2012

\section{References}

1. Wiesner RH, Demetris AJ, Belle SH, Seaberg EC, Lake JR, Zetterman RK, Everhart J, Detre KM: Acute hepatic allograft rejection: incidence, risk factors, and impact on outcome. Hepatology 1998, 28:638-645.

2. Shepherd RW, Shepherd RW, Turmelle Y, Lowell JA, Narkewicz MR, McDiarmid SV, Anand R, Song C: Risk factors for rejection and infection in pediatric liver transplantation. Am J Transplant 2008, 8:396-403.

3. AN INTERNATIONAL PANEL: Banff schema for grading liver allograft rejection: an international consensus document. Hepatology 1997, 25:658-663.

4. Gornicka B, Ziarkiewicz-Wroblewska B, Bogdanska M, Ołdakowska-Jedynak U, Wróblewski T, Morton M, Ziółkowski J, Pączek L, Krawczyk M, Wasiutyński A: Pathomorphological features of acute rejection in patients after orthotopic liver transplantation: Own experience. Transplant Proc 2006, 38:221-225

5. Ramji A, Yoshida EM, Bain VG, Kneteman NM, Scudamore $\mathrm{CH}$, Ma MM, Steinbrecher UP, Gutfreund KS, Erb SR, Partovi N, Chung SW, Shapiro J: Late acute rejection after liver transplantation: the western Canada experience. Liver Transp/ 2002, 18:945-951.

6. Sanchez-Fueyo A, Strom TB: Immunologic basis of graft rejection and tolerance following transplantation of liver or other solid organs. Gastroenterology 2011, 140:51-64.

7. Zhu CL, Huang Q, Liu CH, Xie F: Polymorphisms in the cytotoxic Tlymphocyte antigen 4 gene and acute rejection risk in transplant recipients. Mol Biol Rep 2012, 39:8701-8708.

8. Kubota N, Sugitani M, Takano S: Correlation between acute rejection severity and CD8-positive T cells in living related liver transplantation. Transpl Immunol 2006, 16:60-64.

9. Donckier V, Craciun L, Lucidi V, Buggenhout A, Troisi R, Rogiers X, Boon N, Gustot T, Moreno C, Bourgeois N, Colle I, Van Vlierberghe H, Nagy N, Praet M, Dernies T, Amrani M, Stordeur P, de Hemptinne B, Goldman M: Acute liver transplant rejection upon immunosuppression withdrawal in a 
tolerance induction trial: potential role of IFN-gamma-secreting CD8+ T cells. Transplantation 2009, 87(suppl 9):91-95.

10. Ogura Y, Martinez OM, Villanueva JC: Apoptosis and allograft rejection in the absence of CD8+ T cells. Transplantation 2001, 71:1827-1834.

11. Nickel P, Lacha J, Ode-Hakim S: Cytotoxic effector molecule gene expression in acute renal allgraft rejection: correlation with clinical outcome; histopathology and function of the allograft. Transplantation 2001, 72:1158-1161

12. Yan Q, Wang B, Sui W, Zou G, Chen H, Xie S, Zou H: Expression of GSK-3 $\beta$ in renal allograft tissue and its significance in pathogenesis of chronic allograft dysfunction. Diagn Pathol 2012, 7:5-10.

13. Shulzhenko N, Morgun A, Zheng XX, Diniz RV, Almeida DR, Ma N, Strom TB, Gerbase-DeLima M: Intragraft activation of genes encoding cytotoxic T lymphocyte effector molecules procedes the histological evidence of rejection in human cardiac transplantation. Transplantation 2001, 72:1705-1708.

14. D'Errico A, Corti B, Pinna AD: Granzyme B and perforin as predictive markers for acute rejection in human intestinal transplantation. Transplant Proc 2003, 35:3061-3065.

15. Meehan SM, McCluskey RT, Pascual M, Preffer Fl, Anderson P, Schlossman SF, Colvin RB: Cytotoxicity and apoptosis in human renal allografts: identification, distribution, and quantitation of cells with a cytotoxic granule protein GMP-17 (TIA-1) and cells with fragmented nuclear DNA. Lab Invest 1997, 76:639-649.

16. Gomez-Manero N, Herrero J, Quiroga J, Sangro B, Pardo F, Cienfuegos JA, Prieto J: Prognostic model for early acute rejection after. Liver Transp/ 2001, 7:246-254

17. Neil DA, Hübscher SG: Current views on rejection pathology in liver transplantation. Transplant Int 2010, 23:971-983.

18. Barry M, Bleackley RC: Cytotoxic T lymphocytes all roads lead to death. Nat Rev Immunol 2002, 2:401-409.

19. Trapani JA, Smyth MJ: Functional significance of the perforin/granzyme cell death pathway. Nat Rev Immunol 2002, 2:735-747.

20. Kuijf ML, Kwekkeboom J, Kuijpers MA, Willems M, Zondervan PE, Niesters HG, Hop WC, Erik Hack C, Paavonen T, Höckerstedt K, Tilanus HW, Lautenschlager I, Metselaar HJ: Granzyme expression in fine-needle aspirates from liver allografts is increased during acute rejection. Liver Transpl 2002, 8:952-956.

21. Li XK, Kita Y, Tamura A: Activation of Fas and perforin pathways in rat liver allograft rejection. Transplant Proc 1998, 30:19-21.

22. Krams SM, Villanueva JC, Quinn MB: Expression of the cytotoxic T cell mediator granzyme B during liver allograft rejection. Transpl Immunol 1995, 3:162-166.

23. Ji J, Yu YY, Chen H: Perforin and granzyme B expression in liver allograft rejection. Zhonghua Gan Zang Bing Za Zhi 2004, 12:325-328.

24. Sawada T, Shimizu A, Kubota K, Fuchinoue S, Teraoka S: Lobular damage caused by cellular and humoral immunity in liver allograft rejection. Clin Transplant 2005, 19:110-114.

25. Zhang ZX, Wang S, Huang X, Min W, Sun, Liu W, Garcia B, Jevnikar AM: NK cells induce apoptosis in tubular epithelial cells and contribute to renal ischemia-reperfusion injury. J Immunol 2008, 181:7489-7498.

26. Del Gatto Konczak F, Bourgeois CF, Le Guiner C: The RNA-binding protein TIA-1 is a novel mammalian splicing regulator acting through intron sequences adjacent to a 5/ splice site. Mol Cell Biol 2000, 20:6287-6299.

27. Medley QG, Kedersha N, O'Brien S, Tian Q, Schlossman SF, Streuli M, Anderson P: Characterization of GMP-17, granule membrane protein moves to the plasma membrane of natural killer cells following target cell recognition. Proc Natl Acad Sci USA 1996, 93:685-689.

28. Hong SW, Jeong HJ, Kim SI, Moon JI, Kim YS, Park K: Granzyme B and TIA-1 expression in chronic and acute on chronic renal allograft rejection. Yonsei Med J 2001, 42:285-290

29. Yan Q, Sui W, Wang B, Zou H, Zou G, Luo H: Expression of MMP-2 and TIMP-1 in renal tissue of patients with chronic active antibody-mediated renal graft rejection. Diagn Pathol, in press.

doi:10.1186/1746-1596-7-148

Cite this article as: Cheng et al.: Local distribution analysis of cytotoxic molecules in liver allograft is helpful for the diagnosis of acute cellular rejection after orthotopic liver transplantation. Diagnostic Pathology 2012 7:148.

\section{Submit your next manuscript to BioMed Central and take full advantage of:}

- Convenient online submission

- Thorough peer review

- No space constraints or color figure charges

- Immediate publication on acceptance

- Inclusion in PubMed, CAS, Scopus and Google Scholar

- Research which is freely available for redistribution 